\title{
Ocorrência de lesões hepáticas provocadas por larvas de Strongylus spp diagnosticadas no exame post mortem de equiídeos abatidos em Apucarana, Paraná
}

\author{
Occurrence of hepatic lesions caused by Strongylus spp \\ larvae diagnosed in post mortem exam in horses slaughtered in \\ Apucarana, state of Paraná
}

\author{
Gercio Luiz Bonesi ${ }^{1 *}$; Germano Francisco Biondi²; Cláudio Severino Mattos ${ }^{3}$; \\ Tiago Torrecillas Sturion ${ }^{4}$; Werner Okano ${ }^{5}$
}

\section{Resumo}

\begin{abstract}
O objetivo deste estudo foi determinar a ocorrência de lesões hepáticas provocadas por larvas de estrongilídeos em eqüídeos abatidos em matadouro-frigorífico no Paraná, diagnosticado durante o exame post mortem e estudo macro e microscópico destas lesões. Foram pesquisados nos meses de abril de 2003 a abril de 2004, 38.363 animais, procedentes de diversos estados do país. A ocorrência de granulomas no fígado foi observada em $14.443(37,64 \%)$, com aderências e manchas em $6.645(17,32 \%)$, e sem lesões macroscópicas em 17.275 (45.03\%). Macroscopicamente, foram verificados fígados com nódulos calcificados, presença de manchas esbranquiçadas, aderências e em forma de "linhas" sob a cápsula hepática. Não foram encontradas as larvas nos fígados. Histologicamente, os fragmentos hepáticos revelaram na microscopia óptica, células inflamatórias com o predomínio de eosinófilos ao redor dos granulomas, com moderada quantidade de macrófagos e presença de fibroblastos.
\end{abstract}

Palavras-chave: Eqüídeos, Strongylus spp, lesões hepáticas, fígado

\begin{abstract}
The objective of this study was to determinate the occurrence of hepatic lesions caused by migratory large Strongyle larvaes in horses slaughtered in city of Apucarana in state of Paraná. The lesions were diagnostic in post mortem exam by macro and microscopic analysis. From April 2003 to April 2004, 38,363 animals, coming from different regions of Brazil, were examined. The occurrence of granulomas in liver was observed in 14,443 (37.64\%), with adhesions and spot in 6,645 (17,32\%), and 17,275 (45.03\%) without macroscopic lesions. Macroscopic analysis revealed the presence of livers with calcified nodules, the presence of whitish spots, and adhesions in the format of "lines" over the hepatic capsule. No larvae were found in the livers. Hepatic fragments were histologically processed and revealed, by optical microscopy, inflammatory cells with predominance of eosinophils around the granulomas with a moderate amount of macrophages and the presence of fibroblasts.
\end{abstract}

Key words: Horses, Strongylus spp, hepatic lesions, liver

\footnotetext{
1 Doutor em Inspeção de Produtos de Origem Animal pela Faculdade de Medicina Veterinária e Zootecnia - Universidade Estadual "Julio de Mesquita Filho", Botucatu-SP. E-mail: gercio@sercomtel.com.br.

2 Professor Doutor da Faculdade de Medicina Veterinária e Zootecnia Universidade Estadual "Julio de Mesquita Filho", BotucatuSP, Medicina Veterinária.

3 Médico Veterinário do Serviço de Inspeção Federal (SIF-55) credenciado pelo MAPA, Apucarana-Pr.

4 Médico Veterinário, Centro de Diagnóstico e Apoio Veterinário, Londrina-Pr.

5 Professor do curso Medicina Veterinária Universidade Norte do Paraná - UNOPAR, Arapongas-Pr.

* Autor para correspondência
} 


\section{Introdução}

A produção de carnes em geral é uma atividade muito importante para a economia brasileira. Neste prisma, o crescimento nas áreas da genética, nutrição animal, tecnológica e seu processamento industrial e sanitário permitiram a instalação de indústrias altamente eficientes e competitivas no cenário do país (CASTILLO, 2001).

A importância dos eqüinos na economia industrial é expressiva em vários países do mundo, e o impacto do parasitismo sobre a indústria está bem documentado, resultando em alterações em diferentes sistemas do organismo animal (KLEI et al., 1984).

Dentre os parasitas de eqüídeos destacam-se os helmintos gastrintestinais e os Strongylus spp cuja importância decorre das migrações larvares comprometendo a saúde do hospedeiro por afetar órgãos vitais do animal (HERD, 1986; GOMEZ; GEORGI, 1991; BOWMAN; LYNN, 1999; SOUTO MAIOR; ALVES, 2000).

Em relação às migrações das larvas em orgãos, destacam-se duas espécies: S. edentatus (LOOS, 1902) e $S$. equinus (MÜLLER, 1780) (LICHTENFELS, 1975). As larvas no estágio $\mathrm{L}_{4} \mathrm{de}$ $S$. edentatus migram e invadem o fígado por um período de aproximadamente oito semanas. $\mathrm{Na}$ cavidade abdominal, já como larvas do $5^{\circ}$ estádio produzem nódulos hemorrágicos ou edematosos os quais variam de tamanho entre um a vários centímetros de diâmetro (SOULSBY, 1982; URQUHART et al., 1996). Larvas da espécie $S$. equinus emergem dos cistos (parede do intestino) e se transformam em $\mathrm{L}_{4}$ migrando pela cavidade peritoneal e serosa em direção também ao fígado até chegarem à região do pâncreas transformandose em L $\mathrm{L}_{5}$ (McCRAW; SLOCOMBE 1985; DRUDGE; LYONS; TOLLIVER, 1989). Ocasionalmente, os parasitas podem atingir a gordura perirenal, diafragma, omento e pulmões (McCRAW; SLOCOMBE, 1985).
O objetivo deste trabalho foi determinar a freqüência de ocorrência de lesões hepáticas provocadas por larvas migratórias de estrongilídeos (Nematoda: Strongyloidea) de eqüídeos abatidos em matadouro-frigorífico e descrever os aspectos patológicos macro e microscópico.

\section{Material e Métodos}

O local utilizado para este estudo foi um matadouro-frigorífico de eqüídeos, localizado no município de Apucarana-Paraná. Este estabelecimento industrial é exportador de carne eqüina aos países da União Européia, com Serviço de Inspeção Federal (SIF).

Como estudo foi avaliar a freqüência de ocorrência durante o período de abril de 2003 a abril de 2004 envolvendo animais de abate. Foram estudados 38.363 eqüídeos abatidos, de diferentes idades, ambos os sexos e procedentes de diferentes estados da federação. Tal pesquisa consistiu em observar as lesões em fígados durante o exame post mortem. Após a evisceração da carcaça, o fígado era depositado na mesa rolante para exame e estudo através da observação macroscópica quanto à presença e ausência de lesões hepáticas e, colheita de fragmentos de fígado para estudo microscópico.

A caracterização macroscópica das lesões parasitárias provocadas pelas larvas em fígado foi classificada em três categorias: tipo A, presença de lesões nodulares (granulomas ou nódulos parasitários); tipo $\mathrm{B}$, presença de manchas e/ou aderências; e tipo $\mathrm{C}$, ausência de lesões patológicas no exame post mortem. As lesões granulomatosas com manchas e aderências foram computadas na primeira categoria.

As colheitas de fragmento hepático para avaliação microscópica foram obtidas durante o abate de 135 animais oriundos de 10 lotes, selecionados aleatoriamente, de várias procedências. As respectivas amostras foram acondicionadas em frascos plásticos contendo formalina neutra 
tamponada a 10\%, identificados à data e número da amostra e encaminhados ao Laboratório de Histopatologia Veterinária da Universidade Norte do Paraná (UNOPAR) em Arapongas, Paraná, para serem processadas.

A técnica histológica aplicada consistiu após fixação, na inclusão em parafina, laminação em micrótomo a 5 $\mu \mathrm{m}$ de espessura, coloração pela hematoxilina-eosina (H\&E) e exame ao microscópio óptico.

\section{Resultados}

A Figura 1 apresenta os resultados de distribuição de lesões hepáticas nos diferentes períodos estudados e mostra que há uma tendência cíclica nos resultados dos períodos estudados mantendo-se constante em relação à presença de granulomas, tanto para nódulos quanto para manchas e aderências hepáticas. Muito embora, tenha havido queda no número de animais abatidos no mês dezembro/03, a relação permaneceu a mesma.

\section{Distribuição de lesões hepáticas (\%)}

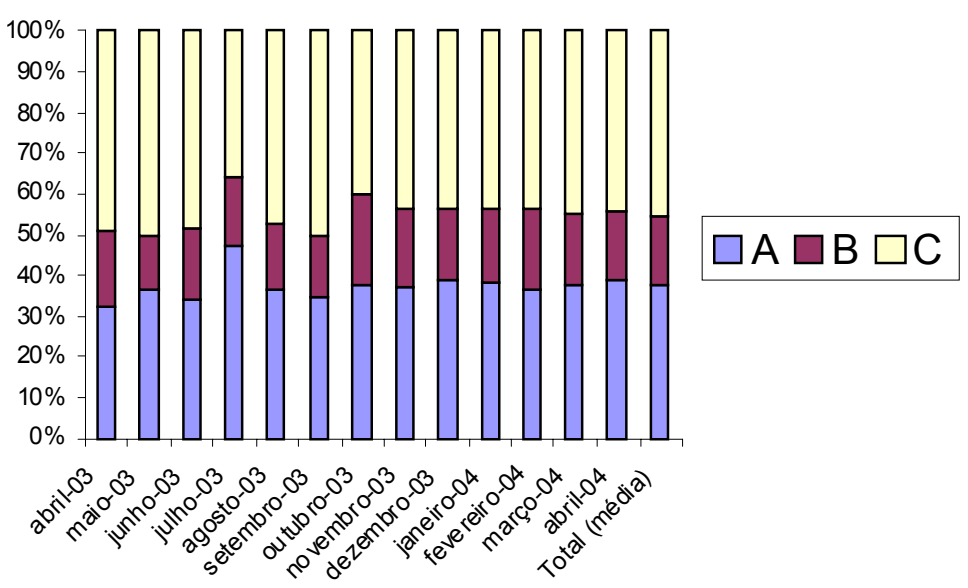

Figura 1. Distribuição das lesões hepáticas por larvas migratórias em eqüídeos, nos diferentes períodos estudados. A $=$ Granulomas, $\mathrm{B}=$ Manchas e Aderências, $\mathrm{C}=$ Ausência de Lesões.

O achado patológico macroscópico mais comum verificado nas rotinas de exame post mortem de fígados em eqüídeos abatidos foi à presença de granulomas (Figura $2 \mathrm{~A}$ ). Estes apresentavam na sua grande maioria, o formato nodular, mas também foram verificadas as formas sinuosas e espiraladas com coloração esbranquiçada e/ou cremosa (Figura 2 B). Os nódulos apresentaram-se numa grande maioria, endurecidos, devido à calcificação, lembravam grãos de areia quando incisados. Esta granulação calcificada assemelhava-se à possível presença de larvas mortas de estrôngilos encarceradas no interior dos tecidos. À palpação, os fígados também estavam firmes pela condensação do estroma ou aglomeração de lesões fibrosadas, principalmente quando as lesões tornavam-se consolidadas, inclusive nos bordos do órgão (Figura 3 B). Quando verificado na fase crônica do processo inflamatório, desaparecia a consistência friável característica do órgão e a ao corte das estruturas hepáticas revelou um ranger da incisão da faca devido às calcificações. Quanto ao tamanho das nodulações, na sua grande maioria, eram inferiores a $1,0 \mathrm{~cm}$ de espessura. Não foi observada a presença de larvas na superfície ou no tecido hepático. 

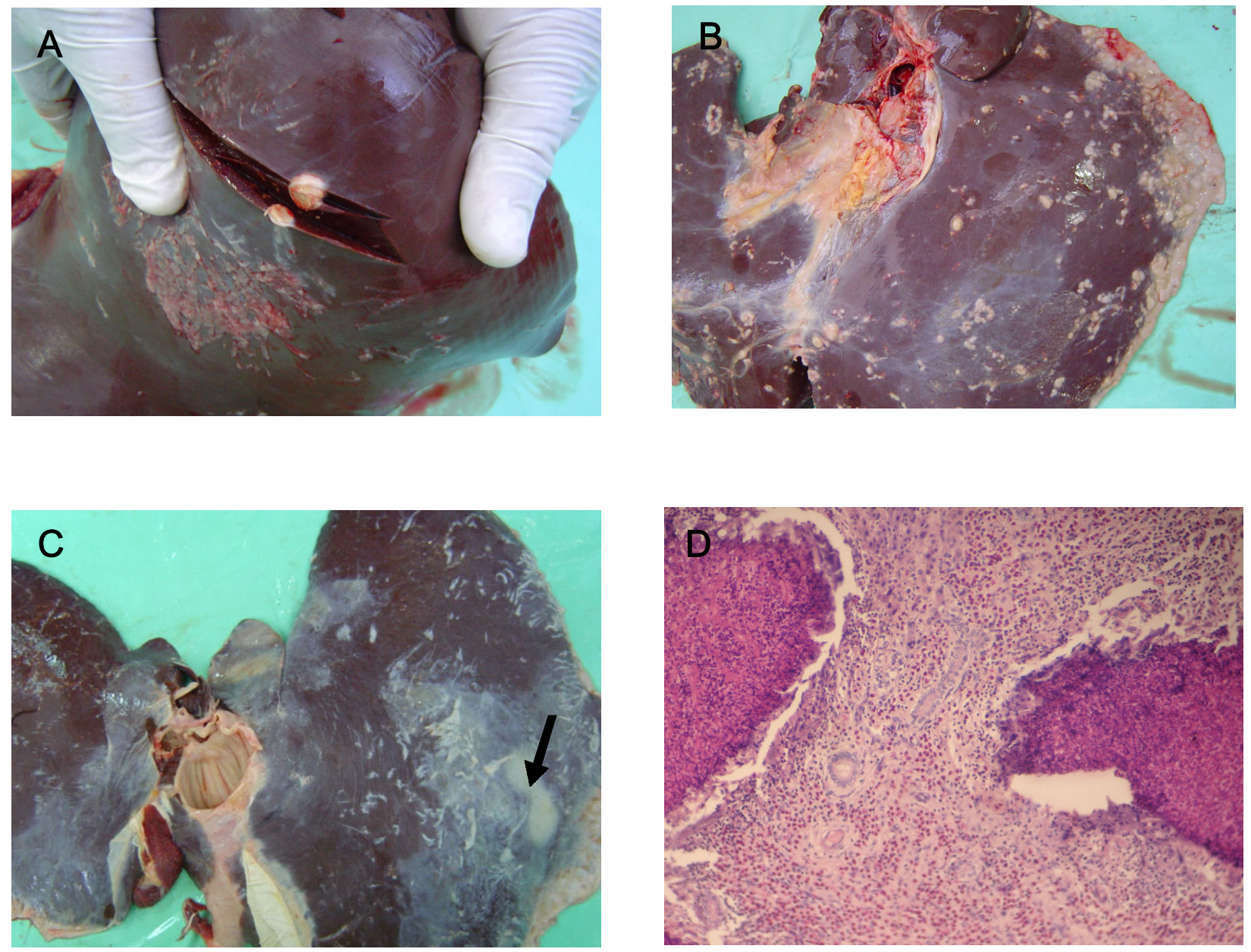

Figura 2. Lesões macro e microscópica de fígados de eqüídeos por larvas migratórias de Strongylus spp, no exame post mortem e histopatologia. A = Granuloma parasitário; $\mathrm{B}=$ Granulomas parasitários calcificados e coalescentes concentrados mais na borda direita do órgão; $\mathrm{C}=$ Fibrose capsular sobre a superfície do órgão. Presença de aderências, estrias de tecidos como "fibras, linhas ou filetes" distribuídos sobre a serosa hepática, acompanhado de manchas esbranquiçadas (seta); D = Fotomicrografia de corte histológico corado com HE. Visualizam-se dois granulomas, lateralmente, com presença de numerosas células eosinofílicas (Objetiva de 10X).

O revestimento seroso hepático apresentava manchas esbranquiçadas, leitosas, às vezes mais amareladas, cremosas ou levemente acinzentadas, sendo um dos achados freqüentes nas rotinas do post mortem. Elas variavam em tamanho, formato e distribuição. Não havia manchas encobrindo toda a túnica hepática. Também foram observadas na cápsula hepática, aderências como pequenos filetes fibrosos em forma de "pontas soltas ou linhas", muitas vezes acompanhadas pelas manchas (Figura $2 \mathrm{C}$ ).
Todos os fígados inspecionados pelo SIF do matadouro que apresentavam lesões hepáticas com granulomas parasitários, manchas, aderências eram julgados e condenados totalmente nas rotinas do exame post mortem.

Os resultados de ocorrência de achados post mortem no fígado estão demonstrados na Tabela 1 . 
Tabela 1. Ocorrência mensal de lesões hepáticas causadas por larvas migratórias, diagnosticadas macroscopicamente no exame post mortem em eqüídeos abatidos - período de abril de 2003 a abril de 2004, em Apucarana-PR.

\begin{tabular}{lcccc}
\hline Meses & $\begin{array}{c}\text { Tipo A* } \\
\text { (No / \%) }\end{array}$ & $\begin{array}{c}\text { Tipo B } \\
\text { (No / \%) }\end{array}$ & $\begin{array}{c}\text { Tipo C } \\
(\text { No } / \%)\end{array}$ & $\begin{array}{c}\text { Total } \\
\text { (No. })\end{array}$ \\
\hline Abril/03 & $458(32,30)$ & $267(18,83)$ & $693(48,87)$ & 1.418 \\
Maio/03 & $1.314(36,36)$ & $490(13,56)$ & $1.810(50,08)$ & 3.614 \\
Junho/03 & $1.323(34,30)$ & $656(17,01)$ & $1.878(48,69)$ & 3.857 \\
Julho/03 & $1.817(47,15)$ & $658(17,07)$ & $1.379(35,78)$ & 3.854 \\
Agosto/03 & $1.168(36,55)$ & $525(16,43)$ & $1.503(47,03)$ & 3.196 \\
Setembro/03 & $1.289(34,59)$ & $571(15,32)$ & $1.867(50,09)$ & 3.727 \\
Outubro/03 & $1.022(37,81)$ & $606(22,42)$ & $1.075(39,77)$ & 2.703 \\
Novembro/03 & $969(36,83)$ & $507(19,27)$ & $1.155(43,90)$ & 2.631 \\
Dezembro/03 & $294(38,79)$ & $132(17,41)$ & $332(43,80)$ & 758 \\
Janeiro/04 & $1.074(38,32)$ & $498(17,77)$ & $1.231(43,92)$ & 2.803 \\
Fevereiro/04 & $1.152(36,75)$ & $609(19,43)$ & $1.374(43,83)$ & 3.135 \\
Março/04 & $1.617(38,04)$ & $724(17,03)$ & $1.910(44,93)$ & 4.251 \\
Abril/04 & $946(39,16)$ & $402(16,64)$ & $1.068(44,21)$ & 2.416 \\
Total (\%) & $14.443(37,46)^{\mathrm{a}}$ & $6.645(17,55)^{\mathrm{b}}$ & $17.275(44.99)^{\mathrm{a}}$ & $38.363(100)$ \\
Média & 1.111 & 511,15 & $1.328,84$ & $2.951,00$ \\
Desvio Padrão & 411,07 & 164,85 & 480,06 & $1.013,87$ \\
\hline
\end{tabular}

*fígados com nódulos ou com nódulos e manchas, concomitante.

Letras diferentes nas colunas indicam diferença estatística $(0,05)$.

Tipo A (granulomas) Tipo B (manchas e aderências) Tipo C (ausência de lesões hepáticas)

A microscopia óptica revelou ao redor dos granulomas células inflamatórias com o predomínio de eosinófilos e moderada quantidade de macrófagos e presença de fibroblastos (Figura 2 D). Em alguns fragmentos a cápsula hepática exibia fibrose intensa. Os fígados apresentaram uma fibrose difusa, com morte dos hepatócitos. Os fígados contendo numerosos nódulos parasitários e com tecido cicatricial apresentavam trajetos migratórios pela passagem de larvas pelo tecido hepático, estando associados às áreas de cicatrizes presentes na cápsula hepática como depósito de fibrina, caracterizando uma peri-hepatite fibrinosa. Outras alterações histopatológicas presentes foram: degeneração hidrópica, degeneração gordurosa microvacuolar, necrose de coagulação, presença de fibroblastos e figuras de megalocitose.

\section{Discussão}

Os dados de freqüência de ocorrência de lesões hepáticos revelaram 14.443 (37,64\%) com nodulações parasitárias e 6.645 (17,32\%) fígados com manchas e aderências. Não obstante, a somatória das lesões nodulares presentes com as lesões por manchas e/ou aderências sobem para 54,96\% dos casos, o que representa, mais da metade dos fígados com lesões.

No mês de julho de 2003, ocorreu a maior freqüência de ocorrência com 47,14\% (1.817/3.854) 
dos casos com lesões nodulares, sendo que nos demais meses do ano os dados foram constantes. A situação da endoparasitose eqüina ao longo do período do levantamento tem mostrado poucas variações no período de um ano, isto é, houve uma relação cíclica, de acordo com a Figura 1, o que demonstra a infecção parasitária constante em eqüídeos destinados ao abate quando comparados os dados obtidos entre os diversos períodos do estudo.

Não há na literatura consultada, trabalhos de pesquisa de ocorrência de lesões hepáticas em eqüídeos abatidos em matadouro que permita uma comparação, envolvendo achados macroscópicos no exame post mortem em fígados provocados por migração de larvas de Strongylus spp. Há trabalhos que descrevem às lesões macroscópicas em formato nodular e mancha sobre a cápsula hepática obtidas por Slocombe e McCraw (1975) através de inoculação experimental. Freitas (1980) descreve a "hepatite intersticial difusa" no fígado e Petty et al. (1992) a fibrose hepática e formações nodulares calcificadas no fígado e pâncreas provocadas por larvas de S.equinus e S.edentatus.

A presença de nódulos no fígado em maior número causados por nematódeos, segundo Jubb; Kennedy; Palmer (1993); Kelly e Fogarty (1993) produz inflamação hepática e de ductos biliares sendo lesões de curso natural ou acidental. Os resultados provocados por larvas que migram e circulam no tecido hepático tem um poder traumático produzindo fibrose e hepatite intersticial. Estes dados nos dão a dimensão da capacidade e poder de ação das larvas no tecido, pois as lesões hepáticas encontradas nos animais de matadouro no Paraná refletem bem os achados da pesquisa. Freitas (1980) descreve as ações das larvas de $S$. equinus, que após migrarem pelo fígado e também pelo pâncreas, causam destruição do tecido hepático, que mais tarde é substituído por tecido de granulação. Da mesma forma, as altas infecções podem provocar hepatite intersticial difusa com grande infiltração de eosinófilos.
Quanto à formação dos nódulos hepáticos, Jubb, Kennedy e Palmer (1993) afirmam que larvas encravam-se no fígado e acabam morrendo e encapsulando que nada mais é, do que o encarceramento das larvas no interior do fígado, enclausuradas dentro de granulomas.

Estes nódulos também foram observados por McCraw e Slocombe (1978) e Georgi (1990), os quais afirmam que larvas do tipo $\mathrm{L}_{3}$ de S.edentatus da parede do intestino grosso alcançam o fígado pelo sistema porta e enclausuradas transformam-se em $\mathrm{L}_{4}$, dentro de alguns meses. Petty et al. (1992) também identificaram a presença de nódulos parasitários calcificados no fígado.

Soulsby (1982) descreve a patogenicidade das larvas de S.equinus produzindo estas "linhas", fibras ou folhetos fibrinosos no fígado. As lesões devido às migrações provocadas pelas larvas sobre a cápsula do fígado como densos apêndices de fibroses são geralmente encontradas na serosa diafragmática de eqüinos adultos (JUBB; KENNEDY; PALMER, 1993; LYONS; DRUDGE; TOLLIVER, 1986). Os autores afirmam tratar-se de infecção devido à migração de S.edentatus. Jubb, Kennedy e Palmer (1993) também relatam que, as larvas S.edentatus e S.equinus ao realizarem suas migrações passam através do fígado e ligamento hepático e formam "linhas" ou "fibras" devido a seqüelas de migração larval, especialmente de $S$. edentatus. Achados semelhantes também foram obtidos por McCraw e Slocombe (1985).

Uma variedade de helmintos dentre eles os nematódeos produzem inflamação do fígado sendo um grupo dos mais comuns a produzir hepatite. Este achado de necrose parasitária cicatricial e percorrido pelas larvas com formação de tecido fibroblástico produz um infiltrado de eosinófilos na unidade portal (JUBB; KENNEDY; PALMER, 1993; KELLY; FOGARTY, 1993).

Aparici e Cardenas (1990) descrevem como "hepatite subaguda" a formação de granulomas em 
torno de um foco de necrose central comparados a tubérculos, referidos como granulomas parasitários crônicos em torno dos parasitos, com aparecimento de células gigantes multinucleadas e abundância de eosinófilos. McCraw e Slocombe (1978), Slocombe (1985) enfatizam a migração larvar de S.edentatus via veias da parede do intestino e através do fluxo sangüíneo venoso atingindo o fígado e produzindo manchas e focos esbranquiçados e/ou amarelados e às vezes, trajetos hemorrágicos sinuosos. Afirmam tratar-se de acúmulos de células monocucleares e eosinófilos, e desta forma confirma os achados do presente estudo.

McCraw e Slocombe (1978), Drudge, Lyons e Tolliver (1989) ao descreverem sobre as infecções crônicas no fígado com fibrose enfatizam que secundariamente há depósitos de cálcio sobre o ceco, cólon e omento, classificadas como "calcificação distrófica".

Prevalência de nematódeos em eqüídeos abatidos em matadouro em Ontário, Canadá, Slocombe e McCraw (1973) evidenciaram larvas tanto de S.edentatus como S.equinus produziram no fígado áreas brancas focais de 2 a $4 \mathrm{~mm}$ de diâmetro que histologicamente, revelaram agregados de células mononucleares misturados com eosinófilos e aderências e "filetes" finos esbranquiçados com cápsula hepática engrossada. Slocombe (1985) descreve que além destas migrações que as larvas produzem no tecido hepático deixa os bordos engrossados como uma conseqüência da saída das larvas do fígado pelo ligamento hepatorenal para seguir rota ao flanco abdominal. Ficam então, espessos, fibrosados e edematosos. No flanco, as larvas sexualmente imaturas ficam envoltas em material gelatinoso, amarelado e às vezes hemorrágico.

O ciclo dos estrôngilos está relacionado à idade $\mathrm{e}$ ao grau de imunidade dos hospedeiros, a fatores ambientais como a contaminação de pastagens e, a outros fatores relacionados. A alta ocorrência de parasitas em eqüídeos está diretamente ligada às condições clínicas e é fator importante à manutenção de programas de saúde animal o que demonstra que, os animais da faixa etária mais avançada podem representar os mais comprometidos. Perez Mata (1999) afirma a infestação parece mais depender de fatores ligados ao manejo e de períodos de exposição dos animais em determinado pasto do que efeito da idade e sexo dos animais. São fatores importantes que determinam diferenças significativas sobre os níveis de ocorrência: a assistência veterinária, utilização de pastos diversos, programa de uso de anti-helmínticos, seu cumprimento e manejo sanitário.

\section{Conclusões}

Da análise dos resultados obtidos, pode-se concluir que:

Os eqüídeos encaminhados ao matadourofrigorífico para o abate são animais que apresentam altas taxas de lesão hepática por migração de larvas de Strongylus spp, com freqüência de ocorrência de $37,64 \%$ de nódulos parasitários e outros animais com manchas e aderências;

$\mathrm{O}$ exame post mortem identificou como achado patológico de rotina, os granulomas parasitários calcificados e as formações ou manchas leitosas, esbranquiçados acompanhados de aderências e "filetes" finos com cápsula hepática.

O exame microscópico revelou agregados de células mononucleares com eosinófilos caracterizando a "hepatite intersticial parasitária difusa".

A estrongilose é uma infecção comum entre os eqüídeos destinados ao abate em matadourofrigorífico.

\section{Referências}

APARICI, P. C.; CARDENAS, G. G. Infeccion e infestacion. In:__ Patologia general veterinária: I. nosologia. Zaragoza: Acribia, 1990. p.58-62. 
BOWMAN, D. D.; LYNN, R. C. Georgis' parasitology for veterinarians. 7.ed. Philadelphia: W.B. Saunders Company, 1999.

CASTILLO, C. J. C. Qualidade de carcaças e carne de aves. In: CONGRESSO BRASILEIRO DE CIÊNCIA E TECNOLOGIA DE CARNES, 1., 2001, São Pedro. Anais... São Pedro: ITAL, 2001.p. 160-178.

DRUDGE, J. H.; LYONS, E. T.; TOLLIVER, S. C. Strongyles: an update. Equine Practice, Santa Barbara, v. 11, n. 2, p. 43-49, 1989.

FREITAS, M. G. Helmintologia veterinária. Belo Horizonte: Rabelo \& Brasil, 1980.

GEORGI, J. R. Parasitology for veterinarians. 5.ed. Philadelphia: W.B. Saunders Company, 1990.

GOMEZ, H. H.; GEORGI, J. R. Equine helminth infections: control by selective chemotherapy. Equine Veterinary Journal, London, v. 23, n. 3, p. 198-200, 1991.

HERD, R. P. Epidemiological and control of equine Strongylosis at Newmarket. Equine Veterinary Journal, London, v. 18, n. 6, p. 447-452, 1986.

JUBB, K. V. F.; KENNEDY, P. C.; PALMER, N. Pathology of domestic animals. 4.ed. San Diego: Academic Press, 1993. v. 2.

KLEI, T. R.; BELLO, T. R.; CLAYTON, H. M.; DIPIETRO, J. A.; DRUDGE, J. H.; LYONS, E. T.; MOORE, J. N.; SLOCOMBE, J. O.; STILLER, D. Research needs on the internal parasites of horses. American Journal of Veterinary Research, Chicago, v. 45, n. 8, p. 1614-1618, 1984.

KELLY, J. C.; FOGARTY, U. M. C. Ourbreakof larval cyathostomiases on a Throughbred stud farm. Irish Veterinary Journal, Dublin, v. 46, p. 133-136, 1993.

LICHTENFELS, J. R. Helminths of domestic equids. Proceedings of the Helminthology Society of Washington, Washington, v.42, n. 1, p. 1-92, 1975. Special Issue.

LYONS, E. T.; DRUDGE, J. H.; TOLLIVER, S. C. Prevalence of Dictyocaulus arnfieldi (Nematoda) in equids and clinical problems with Strongylus vulgaris (Nematoda) mainly in donkeys on a farm in Central Kentucky. Proceedings of the Helminthology Society of Washington, Washington, v. 53, n. 2, p. 251-253, 1986.

McCRAW, B. M.; SLOCOMBE, J. O. D. Strongylus edentatus: development and lesions from ten weeks postinfections to patency. Canadian Journal of Comparative Medicine, Ottawa, v. 42, n. 3, p. 340-356, 1978 .

- Strongylus equinus: development and pathological effects in the equine host. Canadian Journal of Comparative Medicine, Ottawa, v. 49, n. 4, p.372-383, 1985.

PÉREZ MATA, A. M. Estrongilos en caballos pura sangre de carrera en haras de la region central de Venezuela: I. prevalencia mensal. Veterinaria Tropical, Maracay, v. 24, n. 1, p. 55-72, 1999.

PETTY, D. P.; LANGE, A. L.; VERSTER, A.; HATTINGH, J. Necropsies of eight horses infected with Strongylus equinus and Strongylus edentatus. Journal of the South African Veterinary Association, Pretoria, v. 63, n. 2, p. 6669, 1992.

SLOCOMBE, J. O. D. Pathogenesis of helminthes in equines. Veterinary Parasitology, Amsterdam, v. 18, n. 2, p. 139-153, 1985.

SLOCOMBE, J. O. D.; McCRAW, B. M. Gastrointestinal nematodes in the horses in ontario. Canadian Veterinary Journal, Ottawa, v. 14, n. 5, p. 101-105, 1973.

Supression of the pathogenic effects of Strongylus edentatus larvae with thiabendazole. Canadian Journal of Comparative Medicine, Ottawa, v. 39, n. 3, p. 256, Jul. 1975.

SOUTO MAIOR, M. P.; ALVES, L. C. Estrongilose dos eqüídeos. Revista do Conselho Federal de Medicina Veterinária e Zootecnia, Brasília, v. 19, n. 1, p. 39-45, jan.abr. 2000. Suplemento Técnico.

SOULSBY, E. J. L. Helminths, arthrpods of domestic animals. 7.ed. Philadelphia: Lea \& Febiger, 1982.

URQUHART, G. M.; ARMOUR, J.; DUNCAN, J. L.; JENNINGS, F. W. Parasitologia veterinária. 2.ed. Rio de Janeiro: Guanabara Koogan, 1996. 